\title{
Pandangan Mahasiswa Penutur Bahasa Jepang Terhadap Privasi dalam Komunikasi Ditinjau dari Gender
}

\author{
SONDA SANJAYA*1, YURIKO ANDO² \\ 1Program Studi Pendidikan Bahasa Jepang, U niversitas M uhammadiyah \\ Yogyakarta. Jl. Lingkar Selatan, K asihan, Bantul, Yogyakarta 55183, Indonesia \\ E-mail: sonda.sanjaya@umy.ac.id Telp: +6285318952232
}

\begin{abstract}
ABST RAK
Pandangan mahasiswa dan mahasiswi penutur bahasa Jepang terhadap privasi dalam komunikasi yang tidak diketahui dan dipahami para pembelajar bahasa Jepang menyebabkan terjadinya kesalahpahaman dalam komunikasi bahasa Jepang. Guna mengurangi gangguan komunikasi dan kesalahpamahan, maka diperlukan kajian penelitian mengenai privasi dalam komunikasi di kalangan mahasiswa penutur bahasa Jepang berdasarkan gender. Penelitian ini dilakukan dengan metode analisis kontrastif dengan tujuan mengidentifikasi tingkat keterbukaan mahasiswa dan mahasiswi penutur bahasa Jepang mengenai privasi dalam komunikasi, mengidentifikasi faktor penyebab mahasiswa dan mahasiswi penutur bahasa Jepang membicarakan privasi kepada mitra tutur, mengidentifikasi persamaan dan perbedaan respons mahasiswa dan mahasiswi penutur asli bahasa Jepang terhadap topik pembicaraan yang berkaitan dengan privasi. Penelitian ini dilakukan dengan teknik survey dengan mendistribusi kuesioner kepada 109 responden (31 laki-laki dan 78 perempuan). Responden adalah mahasiswa dan mahasiswi penutur asli bahasa Jepang di Jepang. Hasil penelitian menunjukkan bahwa dalam hal privasi mahasiswa penutur bahasa Jepang cenderung lebih tertutup daripada mahasiswi penutur bahasa Jepang. Kemudian, baik mahasiswa maupun mahasiswi penutur bahasa Jepang menilai bahwa faktor yang menyebabkan penutur membicarakan privasi adalah hubungan kepercayaan atau rasa saling percaya. Namun demikian, tingkat intimasi lebih dijadikan faktor pertimbangan bagi mahasiswi penutur bahasa Jepang daripada mahasiswa penutur bahasa Jepang. Kemudian, dalam hal respons terhadap pertanyaan mengenai privasi, mahasiswa penutur bahasa Jepang cenderung lebih tegas untuk tidak menyampaikan informasi privasi daripada mahasiswi penutur bahasa Jepang.

Kata kunci : privasi; komunikasi; analisis kontrastif; gender
\end{abstract}

\begin{abstract}
Lack of knowledge about topics in conversation that Japanese native speaker college students consider as privacy can hinder a successful communication between Japanese native speaker college students and Japanese language learners. To avoid these miscommunication and misunderstanding, more insights gained through studies on privacy in communication among female and male Japanese native speaker college students. This contrastive analysis study aimed at identifying the degree of openness on talking about
\end{abstract}


topics considered as privacy, causing factors of opening up on talking about private topics to their interlocutors, and similarities and differences of responses between male and female Japanese native speaker college students. Employing survey design, a questionnaire on privacy was distributed to 109 participants, including 31 male and 78 female Japanese native speaker college students. The findings of the study showed that male Japanes native speaker college students tended to have a lower degree of openness in comparison to their female counterparts. Additionally, both male and female Japanese native speaker college students considered that the degree of intimacy and trust are two main factors affecting their decision to open up talking about private topics. However, females tended to take the degree of intimacy into consideration when opening up in comparison to their male counterparts. Besides, another finding of this study showed that in comparison to female students, male Japanese native speaker college students tended to be more assertive when it came to conveying topics considered as private matters.

Keywords : privacy; intercultural communication; contrastive analysis; gender

\section{PENDAHULUAN}

Indonesia dan Jepang berada pada wilayah yang sama. Keduanya terletak di Asia. Namun demikian latar belakang budaya, sejarah, pola pikir, karakter bangsa yan gterdapat di kedua negara sangat berbeda.

Perbedaan tersebut seringkali menyebabkan kesalahpahaman di antara dua bangsa tersebut terutama dalam hal komunikasi.

Kesalahpahaman dalam komunikasi dapat dihindari jika penutur menyesuaikan diri dengan mitra tuturnya. Terlebih lagi jika mitra tutur adalah orang yang berbeda suku atau bangsanya karena setiap individu (penutur) akan bertahan hidup jika ia mengikuti budaya dan nilai yang berlaku pada kelompok atau komunitasnya.

Dalam konteks komunikasi berbahasa Jepang, pembelajar bahasa Jepang yang ingin berkomunikasi dengan bahasa Jepang dengan baik harus memahami budaya yang membentuk bahasa Jepang agar mampu mempertahankan hubungan baik dengan masyarakat Jepang. Tetapi, permasalahan dalam komunikasi berbahasa akan muncul jika individu, dalam hal ini pembelajar bahasa Jepang, tidak memahami latar belakang budaya yang memengaruhi berbagai macam faktor penting dalam berkomunikasi dengan bahasa Jepang. Dengan demikian, kesalahpahaman di antara pembelajar bahasa Jepang dan masyarakat Jepang akan timbul. 
D armastuti (2013: 51-52) menyatakan bahwa perbedaan latar belakang budaya terkadang menyebabkan masalah apabila simbolsimbol yang digunakan suatu budaya berbeda memberi dampak perbedaan pemaknaan terhadap simbol-simbol tersebut. Perbedaan pemaknaan akan menyebabkan setiap orang berbeda persepsi. Persepsi yang berbeda akan memberi dampak pada pemaknaan komunikasi, baik komunikasi verbal maupun nonverbal.

Pendapat lain yang dinyatakan Sihabudin (2013: 21) bahwa komunikasi antarbudaya berlangsung apabila suatu anggota masyarakat budaya menyampaikan pesan kepada anggota masyarakat budaya lainnya. Pada kondisi semacam itu, penutur dari suatu anggota masyarakat harus menyandi pesan dalam budaya mitra tutur dan mitra tutur yang lainnya harus menyandi balik sesuai dengan budaya penutur.

Salah satu contoh bentuk komunikasi yang berbeda baik bangsa maupun negaranya, yaitu bangsa Jepang dan bangsa Amerika. Salah satu penyebab perbedaan tersebut terjadi karena bahasa Jepang memiliki high context culture yakni, cenderung menyampaikan pesan dengan implisit sedangkan bahasa Inggris, bahasa resmi bangsa A merika, memiliki low context culture yakni, cenderung menyampaikan pesan dengan eksplisit.

Perbedaan konsep komunikasi bangsa Jepang yang memiliki high context culture dan bangsa A merika yang memiliki low context culture menimbulkan perbedaan harapan di antara kedua bangsa tersebut saat bernegosiasi. Melihat hal tersebut, kita perlu memiliki pengetahuan aturan komunikasi mitra tutur (Sano, Mizuochi \& Suzuki, 1995: 81).

Jika melihat paparan di atas, peneliti berpendapat bahwa pembelajar bahasa Jepang perlu memiliki pengetahuan tentang budaya dan unsur-unsur pembentuk budaya bangsa Jepang sehingga mampu menyandi pesan dari penutur bahasa Jepang dan menyandi balik dengan baik. Selain itu, pemahaman aturan atau pola komunikasi penutur bahasa Jepang yang memiliki budayanya berbeda sangat dibutuhkan. Pada akhirnya, 
komunikasi dengan bahasa Jepang akan berjalan baik tanpa kesalahpahaman.

Perbedaan lain seperti perbedaan latar belakang sosial pun memengaruhi pola dan strategi komunikasi. Pada aspek sosial terdapat perbedaan antara masyarakat Indonesia dan masyarakat Jepang. Salah satu contohnya adalah hal-hal yang berkaitan dengan privasi. Bagi masyarakat J epang al amat rumah merupakan bagian dari privasi. Namun belum tentu bagi masyarakat Indonesia. Ketidakpahaman ranah privasi masyarakat Jepang oleh masyarakat Indonesia berpotensi menimbulkan kesalahpahaman dan hambatan dalam komunikasi.

Menurut KBBI (2005) privasi adalah kebebasan atau keleluasan pribadi. D ari segi sifatnya, M oore (2008) menyatakan bahwa privasi itu bersifat kultural dan kebenerannya dinilai relatif.

Lebih lanjut, Sanjaya dan Ando (2017) menyatakan bahwa privasi adalah hal-hal yang berhubungan dengan kebebasan (barang atau informasi) yang dimiliki oleh seseorang dan dapat secara leluasa menjaganya gangguan orang lain. Artinya, jika dikaitkan dengan komunikasi, maka privasi dalam komunikasi adalah informasi yang dijaga atau dilindugin oleh penutur saat berkomunikasi.

Pandangan terhadap privasi memengaruhi gaya dan strategi komunikasi berbahasa Jepang. Seperti contoh yang telah dikemukakan di atas, masyarakat Jepang tidak suka jika ditanyai alamat rumah. Menanyakan hal tersebut merupakan hal yang dianggap tidak sopan bagi penutur bahasa Jepang. Namun sayangnya, masih cukup banyak pembelajar bahasa Jepang dari Indonesia yang belum memahami bahwa hal tersebut masuk ke dalam ranah privasi masyarakat Jepang.

U ntuk mengatasi permasalahan yang telah dipaparkan di atas, sosiolinguistik sebagai ilmu antardisiplin antara sosiologi dan linguistik berperan sebagai pedoman dalam berkomunikasi dan berinteraksi kepada mitra tutur dengan menunjukkan bahasa, 
ragam bahasa atau gaya bahasa (C haer, dan A gustina, 2004: 7). Melalui melakukan kajian dengan tinjauan sosiolinguistik, permasalahan komunikasi antarbudaya bisa terselesaikan. Sehingga komunikasi pembelajar bahasa Jepang den gan penutur bahasa Jepang akan berjalan lancar.

Penelitian mengenai privasi dalam komunikasi sudah dikaji sebelumnya oleh Sonda Sanjaya dan Yuriko Ando. Pada penelitian terdahulu (Sanjaya \& Ando, 2017) yang mengkaji analisis kontrastif pandangan mahasiswa penutur bahasa Indonesia dan mahasiswa penutur bahasa Jepang terhadap privasi dalam komunikasi ditemukan beberapa hal seperti berikut.

a. M ahasiswa penutur bahasa Indonesia lebih terbuka terhadap privasi daripada mahasiswa penutur bahasa Jepang.

b. Mahasiswa penutur bahasa Jepang membicarakan privasi terhadap mitra tutur sembari mempertimbangkan apakah terdapat hubungan kepercayaan atau tidak pada mitra tutur.

c. Mahasiswa penutur bahasa Indonesia memutuskan akan membicarakan hal yang berkaitan dengan privasi atau tidak setelah memastikan apakah ada hubungan kepercayaan atau tidak dengan mitra tutur.

d. Penyampaian informasi privasi mahasiswa penutur bahasa Jepang dilakukan di tengah proses pertimbangan mengenai hubungan den gan mitratutur saat berkomunikasi, sedangkan penyampaian informasi privasi mahasiswa penutur bahasa Indonesia dilakukan setelah adanya konfirmasi mengenai hubungan dengan mitra tutur.

Melihat hasil penelitian di atap dapat disimpulkan bahwa meskipun mahasiswa penutur bahasa Indonesia lebih terbuka mengenai privasi namun memiliki kecenderungan untuk tidak memberikan informasi seputar privasi den gan tegas kepada pihak atau kelompok orang yang dipastikan tidak memiliki hubungan kepercayaan. Sedangkan mahasiswa pen utur bahasa Jepang yang tidak seterbuka mahasiswa penutur bahasa Indonesia masih memberikan pertimbangan untuk menyampaikan informasi seputar privasi. 
Kajian privasi dalam komunikasi di kalangan mahasiswa masih dianggap luas yakni masih mengkontraskan mahasiswa penutur bahasa Indonesia dan mahasiswa penutur bahasa Jepang. U ntuk itu pada penelitian ini, peneliti memfokuskan pada pandangan mahasiswa penutur bahasa Jepang terhadap privasi dalam komunikasi ditinjau dari gender mengingat bahwa perbedaan laki-laki dan perempuan tercermin dalam praktik linguistik (Padmadewi et. al, 2014:33). Artinya, jika praktik linguistiknya berbeda, maka strategi penutur laki-laki dan perempuan terhadap pembicaraan mengenai privasi pun akan berbeda. Dengan mengetahui perbedaan antara mahasiswa dan mahasiswi penutur bahasa Jepang mengenai privasi dalam komunikasi, pembelajar bahasa Jepang khususnya mahasiswa pembelajar bahasa Jepang lebih memahami strategi komunikasi baik terhadap mahasiswa maupun mahasiswi penutur bahasa Jepang.

Berdasarkan latar belakang yang telah diuraikan sebelumnya, maka penelitian ini dilaksanakan dengan tujuan:

1. mengidentifikasi tingkat keterbukaan mahasiswa dan mahasiswi penutur bahasa Jepang mengenai privasi dalam komunikasi,

2. mengidentifikasi faktor yang menyebabkan mahasiswa dan mahasiswi penutur bahasa Jepang membicarakan privasi kepada mitra tutur,

3. mengidentifikasi persamaan dan perbedaan respons mahasiswa dan mahasiswi penutur asli bahasajepan g terhadap topik pembicaraan yang berkaitan dengan privasi.

\section{METODE PENELITIAN}

Tinjauan yang digunakan dalam penelitian ini adalah tinjauan sosiolinguistik interaksional yang diusulkan oleh Gumperz (2002), sedangkan metode yang digunakan adalah analisis kontrastif, yaitu metode padan ekstralingual. M etode padan ekstralingual merupakan salah satu metode menganalisis bahasa secara sinkronis. M ahsun (2007: 117) menguraikan bahwa kata padan bersinonim dengan kata banding; sehingga metode padan 
ekstralingual dimaknai sebagai sebuah kegiatan menghubungbandingkan antara unsur-unsur yang berada dalam bahasa dengan unsur-unsur yang berada di luar bahasa, seperti hal-hal yang menyan gkut makna, informasi, konteks, tuturan, dan lainlain. M etode ini dapat diterapkan untuk menganalisis unsur lingual yang terdapat dalam bahasa yang berbeda.

Berikut tahapan-tahapan dalam menganalisis data pen elitian ini:

a. mengumpulkan data (hasil angket) dari mahasiswa penutur asli Jepang dan mahasiswi penutur asli bahasa Jepang;

b. membuat kategori data: hal-hal yang masuk ke dalam ranah privasi baik mahasiswa maupun mahasiswi penutur asli bahasa Jepang, kelompok yang boleh mengetahui dan tidak boleh mengetahui privasi mahasiswa dan mahasiswi penutur asli bahasa Jepang, alasan memberi tahu privasi dan alasan tidak memberi tahu privasi, respons penutur (mahasiswa dan mahasiswi penutur asli bahasa Jepang) terhadap mitra tutur yang bertanya tentang privasi;

c. menginput data sesuai kategori yang telah ditentukan;

d. hasil analisis data mahasiswa dan mahasiswi penutur asli bahasa Jepang dibandingkan serta dikontraskan, Ialu mencari titik-titik persamaan dan perbedaan di antara keduanya;

e. menyusun laporan hasil analisis.

Penelitian ini menggunakan teknik survei dengan menggunakan kuesioner yang bertujuan untuk mengukur eksistensi dan distribusi berbagai tingkah laku atau karakteristik secara alami, frekuensi kemunculan kejadian yan terjadi secara al amiah, dan hubun gan serta besarnya hubungan-hubungan yang mungkin ada antara karakteristik, tingkah laku, kejadian atau fenomena yang menjadi perhatian peneliti (Alwasilah, 2009 : 151). Dalam penelitian ini survei dilakukan untuk mengamati dan mengetahui ranah privasi berdasarkan pemikiran mahasiswa dan mahasiswi penutur asli bahasa Jepang, kelompok yang boleh dan tidak boleh mengetahui privasi, dan respons penutur jika ditanyai tentang privasi oleh mitra tutur. 
Jenis kuesioner atau angket yang digunakan adalah kuesioner dengan pertanyaan terbuka dan tertutup (open and cloesd questions). Pemilihan jenis kuesioner tersebut dikarenakan agar responden mudah memberikan jawaban dan memudahkan fokus pada pertanyaan untuk dijawab. Selain itu, peneliti menduga akan ada variasi jawaban lain dan berusaha men cari temuan baru dari setiap responden atau sampel.

Sumber data berasal dari hasil angket yang didistribusi kepada para sampel atau responden yang merupakan mahasiswa dan mahasiswi penutur asli bahasa Jepang. Sampel atau responden adalah mahasiswa dan mahasiswi penutur asli bahasa Jepangyang sedang menempuh studi di perguruan tinggi di Jepang. Jumlah kuesioner yang telah didistribusi kepada mahasiswa penutur asli bahasa Jepang telah didistribusi sebanyak 109 orang. M ahasiswa berjumlah orang 31 dan mahasiswi 78 berjumlah orang. Pembagian kuesioner dilaksanakan di dua tempat, yaitu di Ibaraki U niversity (Prefektur Ibaraki) dan Ryukoku U niversity (Kyoto).

Pertanyaan pada kuesioner terbagi ke dalam en am pertanyaan (klasifikasi) seperti berikut:

a. ruang lingkup (ranah) dianggap privasi bagi mahasiswa dan mahasiswi penutur asli bahasa Jepang,

b. kelompok yang dianggap boleh dan tidak boleh men getahui privasi mahasiswa dan mahasiswi penutur asli bahasa Jepang,

c. alasan mahasiswa dan mahasiswi penutur asli bahasa Jepang memberitahu privasi,

d. respons mahasiswa dan mahasiswi penutur asli bahasa Jepang saat ditanyai privasi oleh orang yang dianggap boleh mengetahuinya,

e. respons mahasiswa dan mahasiswi penutur asli bahasa Jepang saat ditanyai privasi oleh orang yang dianggap tidak boleh mengetahuinya.

Setelah responden memberikan jawaban pada kuesioner, peneliti menghitungjumlah jawaban responden (data) pada setiap pertanyaan. Kemudian, baik data yang diperoleh dari mahasiswa penutur asli bahasa Jepang dan mahasiswi penutur asli bahasa 
Jepang yang telah dikontraskan bisa diamati persamaan dan perbedaannya. Setelah mengetahui persamaan dan perbedaan pada mahasiswa penutur asli bahasa Indonesia dan mahasiswa penutur asli bahasa Jepang, peneliti dapat menarik simpulan.

TABH 1 RUNGUNOKPPAVAS

\begin{tabular}{|c|c|c|c|c|}
\hline \multirow[t]{2}{*}{ Unten } & \multicolumn{2}{|c|}{ MatraisnaPenturBdhesajepang } & \multicolumn{2}{|c|}{ Natesiswi Pentur Baresalepang } \\
\hline & Plihar & Pesatase(\%) & Plikar & Pesertase $(\%)$ \\
\hline 1 & danærund & $T, 42$ & danatrumd & $\notin \notin, 4 k$ \\
\hline 2 & pekejankduaga & 74,19 & rila/ipk & 75,64 \\
\hline 3 & anggdakduagaserdi & 70,97 & kanæsendri & 64,1 \\
\hline 4 & is katungttenpetsanpet & 7,91 & pekejzankdurge & 6,54 \\
\hline 5 & rila/ipk & 6,74 & is katurg'terpetsanpet & $56,4]$ \\
\hline$\epsilon$ & kanærsedri & 64,52 & tangal lahir & $4 \varepsilon, T_{2}$ \\
\hline 7 & tanggal lair & $5 \xi, 0$ & arggdakduargasandi & $4,4,4$ \\
\hline$\varepsilon$ & $\begin{array}{l}\text { nempunai keaihatau } \\
\text { tick }\end{array}$ & 51,6] & renadri & 4,8, \\
\hline $\mathrm{C}$ & ranadri & $4 E, 16$ & nempanji kkaihatatick & 3,74 \\
\hline IC & $\begin{array}{l}\text { pergrailankejapanh } \\
\text { wałtu }\end{array}$ & 41,94 & pengrailankejapanhutkth & $3, \pi$ \\
\hline 11 & caantentkanlibaran & 41,94 & caantentkanlibarn & 30,77 \\
\hline 10 & pekejæanparhutku & 29,03 & petejæanpanhuAtu & 28,27 \\
\hline 1 & hdi & $2 \mathrm{C}, \mathrm{OE}$ & hdd & $2 \leftleftarrows, 0 \varepsilon$ \\
\hline
\end{tabular}

\section{HASIL DAN PEMBAHASAN}

Untuk memudahkan analisis data, seperti yang telah dijelaskan sebelumnya peneliti membagi himpunan data yang diperoleh ke dalam enam klasifikasi pertanyaan. Seperti yang tergambar pada tabel 1, dalam hal ranah atau ruang lingkup privasi baik bagi mahasiswa penutur bahasa Jepang maupun bagi mahasiswi penutur bahasa Jepang menempatkan alamat rumah sebagai hal yang paling dianggap privasi. H asil tersebut sejalan dengan temuan yang diperoleh oleh Tamura (2005) yang menyatakan bahwa alamat rumah dianggap paling privasi $(95,6 \%)$. Sedangkan urutan dua ke bawah terapat perbedaan ruang lingkup dan jumlah yang agak berbeda. Tapi, pada urutan tiga terbawah terdapat kesamaan yaitu, baik bagi mahasiswa penutur bahasa Jepang maupun mahasiswi penutur bahasa 


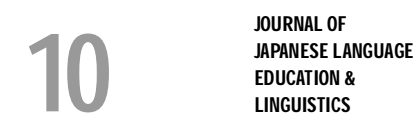

Jepang menilai cara melewatkan liburan, pekerjaan paruh waktu, dan hobi tidak begitu dianggap privasi. Kemudian, jika membandingkan persentase kategori privasi mahasiswa dan mahasiswi penutur bahasa Jepang, bisa dikatakan bahwa dalam hal privasi mahasiswa penutur bahasa Jepang cenderung agak lebih tertutup daripada mahasiswi penutur bahasa Jepang.

Pada tabel 2 dijelaskan bahwa dalam hal kelompok yang dianggap boleh mengetahui privasi, tiga kelompok yang paling dianggap baik mahasiswa maupun mahasiswi penutur bahasa Jepang boleh mengetahui privasinya adalah keluarga sendiri, sahabat, dan kekasih. Namun ada sedikit perbedaan yaitu mahasiswa penutur bahasa epang menempatkan keluarga sebagai pihak yan g dianggap paling boleh mengetahui privasi $(90,32 \%)$, sedangkan mahasiswi penutur bahasa Jepang menempatkan sahabat sebagai pihak yang paling boleh mengetahui privasi $(94,87 \%)$. M elihat ketiga kelompok tersebut sebagai pihak yang dianggap paling boleh mengetahui privasi, bisa disimpulkan bahwa jika hubungan penutur, yakni baik mahasiswa maupun mahasiswi penutur bahasa Jepang dengan mitra tutur semakin dekat atau menjadi bagian kelompok uchi (ingroup) maka semakin memungkinkan untuk memberikan informasi pribadi penutur. $\mathrm{Hal}$ ini sejalan dengan A dams dkk (2009) bahwa penutur Jepang memiliki kecenderungan memberikan informasi pribadi kepada orang yang termasuk ke dalam kelompok uchi. Selain itu, sejalan dengan M aynard dalam O gawa dan Gudykunst (1999) bahwa penutur bahasaJ epang cenderung lebih dekat dengan kelompok uchi yang akrab. Sehingga dengan kedekatan tersebut memungkinkan untuk memperoleh informasi pribadi.

Kemudian, jika melihat urutan ketiga terbawah kelompok yang dianggap boleh mengetahui privasi penutur, baik mahasiswa maupun mahasiswi penutur bahasa Jepang menilai tetangga, penjaga toko atau kantin, dan dosen yang tidak mengampu sebagai pihak yang dianggap tidak boleh mengetahui privasi. $\mathrm{N}$ amun jika dilihat dari persentase, meskipun ketiga kelompok tersebut sama-sama menempati urutan yang sama, mahasiswa 
penutur bahasa Jepang cenderung sangat tegas untuk tidak memberikan informasi yang berhubungan privasi. Sedangkan mahasiswi penutur bahasa Jepang masih cukup memberikan kelonggaran untuk menyampaikan informasi yang berhubungan dengan privasi. U ntuk lebih jelas bisa dilihat pada tabel 2 di bawah ini.

TAEH 2 KHOMPOKYANGDANGCAPBOHHMENCEIAHU PPIVAS PENUTR

\begin{tabular}{|c|c|c|c|c|}
\hline \multirow{2}{*}{ Uhten } & \multicolumn{2}{|c|}{ NaresisnaPenturBdresaleparg } & \multicolumn{2}{|c|}{ Matresiswi PenturBatesajepang } \\
\hline & Pliken & Pesatare(\%) & Pliken & Pestatase $(\%)$ \\
\hline 1 & kduarge & 90,32 & satald & $94,8 /$ \\
\hline 2 & stabd & 87,1 & keluage & 92,31 \\
\hline 3 & keash & 77,4 & kdaih & 82,05 \\
\hline 4 & kedat & 64,52 & kedat & 64,1 \\
\hline 5 & seriardanjurior & 41,94 & seriordanjuiar & 52,56 \\
\hline 6 & dosenperganpu & 25,81 & dosenpenganpu & 48,72 \\
\hline 7 & kerar & 16,13 & kerdar & 26,92 \\
\hline$\varepsilon$ & tetange & 6,45 & tetange & $21, \pi$ \\
\hline $\mathrm{C}$ & pejagatdodkatir & 6,45 & dbsenyengtidknerganpe & $19,2=$ \\
\hline 11 & dosenyengtickknergamp & $3,2=$ & perjagatdkdkatir & 11,54 \\
\hline
\end{tabular}

Seperti yang tergambar pada tabel 3 , alasan yang membuat mahasiswa dan mahasiswi penutur asli bahasa Jepang bersedia menyampaikan informasi tentang privasinya adalah adanya hubungan yang disertai rasa saling percaya. $\mathrm{H}$ al tersebut sejalan dengan pendapat Doi dalam O gawa dan Gudykunst (1999) bahwa seseoran gyang memiliki itikad baik dan memberikan rasa aman akan membentuk hubungan kepercayaan yang membuat mitra tutur merasa aman untuk menyampaikan hal yang berkaitan dengan privasinya kepada mitra tutur dan penutur merasa aman karena mitra tutur akan menjaganya karena tidak akan mengancam (membocorkan privasi) penutur.

M eskipun dilihat dari ranking (urutan) alasan mahasiswa dan 
mahasiswi penutur bahasa Jepang memberikan informasi mengenai privasi sama, terdapat perbedaan pada persentase alasan ranking kelima dan keenam. Dilihat dari alasan tersebut, nampaknya mahasiswi penutur bahasa Jepang cenderung lebih mempertimbangkan faktor intimasi (keakraban) daripada mahasiswa penutur bahasa Jepang.

TAEH 3. ALASANMEVBRI TAHUPAVAS

\begin{tabular}{|c|c|c|c|c|}
\hline \multirow{2}{*}{ Unten } & \multirow{2}{*}{$\begin{array}{l}\text { MaterishaPenturBdesa } \\
\text { Jepang } \\
\text { Plihen }\end{array}$} & \multicolumn{3}{|c|}{ MatexiswipenturBaresajepang } \\
\hline & & $\begin{array}{l}\text { Pesertæe } \\
(\%)\end{array}$ & Plikan & Pessetare(\%) \\
\hline 1 & $\begin{array}{l}\text { kareaAcadannitrattur } \\
\text { salingnmiliki resasding } \\
\text { peraya }\end{array}$ & 87,1 & 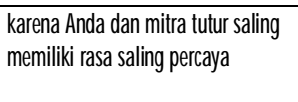 & $88,4 E$ \\
\hline 2 & $\begin{array}{l}\text { karaAnchargatnemgend } \\
\text { mitratturAnca }\end{array}$ & $6, x$ & $\begin{array}{l}\text { kaeraArcasangtinergend } \\
\text { nitratturArca }\end{array}$ & 6, $x$ \\
\hline$\Xi$ & $\begin{array}{l}\text { kareranitattursangt } \\
\text { remgerd Anch }\end{array}$ & 54,84 & $\begin{array}{l}\text { kaeramitratutursangtnergerd } \\
\text { Anca }\end{array}$ & $55,1=$ \\
\hline 4 & 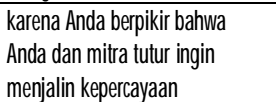 & $38,7]$ & 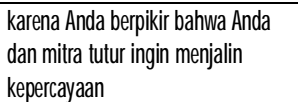 & 39,74 \\
\hline 5 & $\begin{array}{l}\text { kaeraAncabeapkiringin } \\
\text { nergerd nitrattur }\end{array}$ & 35,48 & $\begin{array}{l}\text { kaeraArcaberpikiringin } \\
\text { nengerd nitratutur }\end{array}$ & 14,1 \\
\hline 6 & 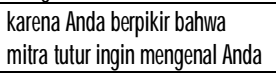 & 35,48 & $\begin{array}{l}\text { kaeraAncaberpikirbahyanitra } \\
\text { thturingnnergeral Anch }\end{array}$ & 12,82 \\
\hline
\end{tabular}

Dalam hal respons saat ditanyai privasi oleh orang yang dianggap boleh mengetahuinya, tergambar pada tabel 4 yakni, baik mahasiswa penutur bahasa Jepang maupun mahasiswi penutur bahasa Jepangadakalanya mempertimbangkan beberapa hal atau situasi untuk membicarakan privasi kepada orang yang dipercaya dan orang yang dikenal. $\mathrm{H}$ al tersebut disebabkan mahasiswa dan mahasiswi penutur bahasa Jepang cenderung tidak hanya menilai apakah mitra tutur termasuk ke dalam kelompok uchi (ingroup) saja tapi juga menilai tingkat intimasinya. Di samping itu, mahasiswa dan mahasiswi penutur bahasa Jepang yang cenderung menerapkan koletivisme yang menggunakan high context communication ( $G$ udykunst dan Ting-Toomey dalam 0 gawa dan Gudykunst, 1999). Sehingga pertanyaan yang berkaitan dengan privasi direspons dengan pertimbangan yangtinggi seperti 
apakah mitra tutur sudah mapuk ke dalam ingroup atau belum dan seberapa intimkah hubungan penutur dan mitra tutur.

Di samping ada kesamaan antara mahasiswa penutur bahasa Jepang dan mahasiswi penutur bahasaJepangyang menunjukkan bahwa mereka mempertimbangkan kedudukan mitra tutur dan tingkat intimasi, ada sedikit perbedaan dalam respons saat ditanyai privasi oleh orang yang dianggap boleh mengetahui privasinya. M ahasiswa penutur bahasa Jepang terkadang berbohong untuk tidak memberikan informasi mengenai privasi $(6,45 \%)$ meskipun mitra tuturnya adalah kelompok yang dianggap boleh mengetahui privasi. $\mathrm{H}$ al itu menunjukkan bahwa ada situasi yang membuat mahasiswa penutur bahasa Jepang enggan memberi tahu privasinya dan lan gkah yan g diambil untuk menutupi privasinya dengan cara berbohong. Sedan gkan itu tidak dilakukan oleh mahasiswi penutur bahasa Jepang (0\%).

TABH 4. REPONSSAATLTANA PPIAS OHHCRANGYANGDANGCAPBOH HMENCEAHUNA

\begin{tabular}{|c|c|c|c|c|}
\hline \multirow[b]{2}{*}{ Unten } & \multicolumn{2}{|l|}{ NatraisnaPenturBatesaleparg } & \multicolumn{2}{|c|}{ Matresiswi Pentur Baresalepang } \\
\hline & Plikan & Pessetase(\%) & Plikan & $\begin{array}{l}\text { Pessetase } \\
(\%)\end{array}$ \\
\hline 1 & 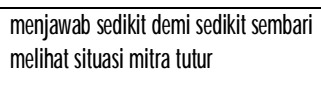 & 80,ஞ & 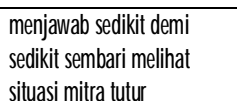 & $87,1 \varepsilon$ \\
\hline 2 & sexpanmjandbserene & $9,6 \subset$ & segpantijanzbseneene & 11,54 \\
\hline$\Xi$ & babdotor & 6,45 & sane soddi ticknerjantk & $C$ \\
\hline 4 & samasddi tickknærjanzk & $\mathrm{C}$ & beabdor & $\mathrm{C}$ \\
\hline
\end{tabular}

Sedangkan dalam hal respons yang ditunjukkan pada orang yang dianggap tidak boleh mengetahui privasi, terdapat perbedaan di antara mahasiswa penutur bahasa Jepang dengan mahasiswi penutur bahasa Jepang. $\mathrm{H}$ al ini tergambar pada tabel 5 yan g menggambarkan bahwa mahasiswa penutur bahasa Jepang cenderung lebih tegas untuk tidak memberikan informasi mengenai privasi kepada orang atau kelompok yang dianggap tidak boleh men getahui privasi. $\mathrm{H}$ al tersebut ditunjukkan dengan pilihan terbanyak yang menyatakan "sama sekali tidak menjawab" sebesar 48,39\%. Sedangkan mahasiswi penutur bahasa Jepang masih cukup mempertimbangkan untuk memberikan informasi 
mengenai privasi kepada orang atau kelompok yang dianggap tidak boleh mengetahui privasi. $\mathrm{H}$ al tersebut bisa dilihat dari pilihan terbanyak yang menyatakan "menjawab sedikit demi sedikit sembari melihat situasi mitra tutur" sebesar $42,31 \%$. Ketegasan mahasiswa penutur bahasa Jepang untuk tidak memberikan informasi mengenai privasi kepada orang yang dianggap tidak boleh men getahuinya dipertegas oleh pilihan yang menyatakan "berbohong" sebesar $25,81 \%$.

TABH 5. REPONSSAATLTANA PRIAG QHHCRANGYANGDANCCAPTIDAKBOHMENGEAHUNA

\begin{tabular}{|c|c|c|c|c|}
\hline \multirow[b]{2}{*}{ LRUAN } & \multicolumn{2}{|c|}{ MAHASS/AFNUILRBA-ASAJIPANG } & \multicolumn{2}{|l|}{ MAHASSWFENUTRBAAASAIEAAG } \\
\hline & RUHAN & $\begin{array}{l}\text { PASANRAE } \\
(\%)\end{array}$ & PUHAN & 円R丹NAEF(\%) \\
\hline 1 & $\begin{array}{l}\text { sanasddil tidk } \\
\text { næijantb }\end{array}$ & 48,39 & 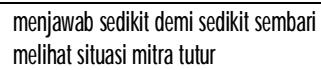 & 42,31 \\
\hline 2 & 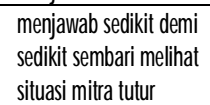 & 25,81 & sanmasddi iddknmjanzb & 30,77 \\
\hline 3 & betboturg & 25,81 & babchory & 16,6 \\
\hline 4 & $\begin{array}{l}\text { seganantianzb } \\
\text { semeena }\end{array}$ & $\mathrm{C}$ & segranmijartbsenoenze & $\mathrm{C}$ \\
\hline
\end{tabular}

\section{PENUTUP}

Berdasarkan hasil analisis dapat disimpulkan bahwa dalam hal privasi mahasiswa penutur bahasa Jepang cenderung lebih tertutup daripada mahasiswi penutur bahasa Jepang. Faktor yang menyebabkan mahasiswa dan mahasiswi menyampaikan informasi mengenai privasi adalah masuknya mitratutur kedalam kelompok uchi (ingroup) dan adanya rasa saling percaya. Namun demikian, ada sedikit perbedaan di antara faktor mahasiswa penutur bahasa Jepang dan mahasiswi penutur bahasa Jepang untuk menyampaikan informasi yang berkaitan dengan privasi, yaitu bagi mahasiswi penutur bahasa Jepang selain mempertimban gkan hubungan kelompok uchi dan adanya rasa saling percaya dan faktor intimasi cenderung lebih dijadikan pertimbangan untuk menyampaikan informasi yang berkaitan 
dengan privasi. Dalam hal respons menerima pertanyaan yang berkaitan dengan privasi dari orang yang dianggap boleh mengetahui privasi, baik mahasiswa maupun mahasiswi penutur bahasa Jepang keduanya akan memberikan jawaban dengan melihat situasi dan kondisi seperti apakah mitra tutur masuk ke dalam kelompok uchi atau tidak dan seberapa tingkat intimasi penutur dengan mitra tutur. Selain itu, terdapat sedikit perbedaan di antara mahasiswa dan mahasiswi penutur bahasa Jepang yaitu, adakalanya mahasiswa penutur bahasa Jepang berbohong untuk tidak menyampaikan informasi privasi sekalipun kepada orang yang dianggap boleh mengetahui privasinya. Sedangkan respons pertanyaan yang berkaitan dengan informasi privasi dari orang yang dianggap tidak boleh mengetahui privasi, mahasiswa penutur bahasa Jepang cenderung lebih tegas untuk tidak menyampaikan informasi privasi daripada mahasiswi penutur bahasa Jepang.

\section{DAFTAR PUSTAKA}

Adams, A. A., Murata, K. and Orito,9ÿ. 2009 ÿ The Japanese sense of information privacy. Al ÿ Society, 24 (4):324-341.

Alwasilah, A. Chaedar. (2009). Pokoknya Kualitatif. Jakarta: Pustaka Jaya.

Chaer, Abdul dan Agustina, Leonie. (2004). Sosiolinguistik Perkenalan Awal. Jakarta: Rineka Cipta.

Darmastuti, Rini. (2013). Mindfullness dalam Komunikasi Antarbudaya. Yogyakarta: Buku Litera.

Gumperz, John J. (2002). Studies in Interactional Sociolinguistics 1 - Discourse Strategies. Cambridge: Cambridge University Press.

Mahsun. (2007). Metode Penelitian Bahasa: tahapan strategi, metode, dan tekniknya. Jakarta: PT Raja Grafindo Persada.

Moore, Adam. (2008). Defining Privacy. Journal of Sociophilosophy, 39(3): 411-428.

Padmadewi, dkk. (2014). Sosiolinguistik. Yogyakarta : Graha IImu

Pusat Bahasa Departemen Pendidikan Nasional. (2005). Kamus Besar Bahasa Indonesia. Jakarta: Balai Pustaka.

Ogawa, Naoto \& Gudykunst, William, B. Politeness Rules in Japan and the United States. Intercultural Communication Studies IX:1 1999-2000.

Sanjaya, Sonda dan Yuriko Ando. (2017). Analisis Kontrastif Pandangan M ahasiswa Penutur Bahasa Indonesia dan Mahasiswa Penutur Bahasa Jepang terhadap Privasi dalam Komunikasi: Sebuah Tinjauan Sosiolinguistik. Japanedu, 2(1): 40-52.

Sano, Masayuki., Mizuochi, Ichiro., Suzuki, Ryuichi. (1995). Ibunka Rikai no Sutorateeji 50 no bunkateki topikku o shiten ni shite. Tokyo: Taishukan Shoten.

Sihabudin, Ahmad. (2013). Komunikasi Antarbudaya Satu Perspektif M ultidimensi. Jakarta: Bumi Aksara.

Tamura, Takanori. (2005). Japanese feeling for privacy. In The 2nd Asia-Pacific Computing and Philosophy Conference (pp. 88-93). 